\title{
Development Strategy for China's Integrated Transportation Engineering Science and Technology to 2035
}

\author{
Zhang Jun $^{1}$, Wang Yunpeng ${ }^{1,2}$, Lu Guangquan ${ }^{1,2}$, Chen Peng ${ }^{1,2}$ \\ 1. Beihang University, Beijing 100191, China \\ 2. Collaborative Innovation Platform of Intelligent Integrated Transportation, Ministry of Transport of the PRC, Beijing 100191, China
}

\begin{abstract}
Integrated transportation faces serious challenges involving safety, high efficiency, and environmental protection given the rapid development of the social economy, and deep application and integration of new-generation information technology. In order to address the main demands of socioeconomic and transportation development, this study involved conducting strategic research on the development trends and paths for integrated transportation engineering science and technology in 2035 based on analyses of the development situation. The study focused on network connections, collaboration, and intelligence. Furthermore, this study included proposing strategic plans, key directions, development paths, and major projects for integrated transportation engineering science and technology in 2035, and all of the fore-mentioned factors could aid in providing valuable insights towards the realization of forward leaps in the development of China's integrated transportation engineering science and technology.
\end{abstract}

Keywords: integrated transportation; 2035; engineering science and technology; strategic plan

\section{Introduction}

Transportation is an important, fundamental, leading, and service industry of a national economy and is an indispensable and irreplaceable part of the social production and life organization system. In this new situation, given the rapid development of social economy, further application, and cross-border integration of new-generation information technology, the development of integrated transportation engineering science and technology continues to face major challenges including safety, efficiency, and environmental protection. To this end, the United States (US), European Union (EU), and other developed countries and regions in the world have formed strategic plans for the development of integrated transportation engineering science and technology. Hence, it is necessary to propose a development strategy and evolution path for integrated transportation engineering science and technology in the year 2035 for China.

\section{Worldwide development prospects of integrated transportation engineering science and technology in $\mathbf{2 0 3 5}$}

\subsection{International frontier of integrated transportation engineering science and technology}

To coordinate various modes of transportation, reasonably allocate and use transportation resources, and use the overall advantages of integrated transportation, the US considered the Vision 2050: An Integrated National Transportation System as a guide and proposed to construct an integrated, international, joint, inclusive, intelligent, and innovative "6I" type of transport system [1]. The EU considered the Transport White Paper as the core and focused on the rational allocation, mutual convergence, and integrated transportation hub construction of road network, public transport network, railway network, and water transport

Received date: 9 December 2016; revised date: 26 December 2016

Corresponding author: Wang Yunpeng, Beihang University, Professor. Major research field is intelligent transportation systems. E-mail: ypwang@buaa.edu.cn Funding program: CAE Advisory Project “Research on China's Engineering Science and Technology Development Strategy 2035” (2015-ZD-14)

Chinese version: Strategic Study of CAE 2017, 19 (1): 043-049

Cited item: Wang Yunpeng et al. Development Strategy for China's Integrated Transportation Engineering Science and Technology to 2035. Strategic Study of CAE, https://doi.org/10.15302/J-SSCAE-2017.01.007 
network to construct an efficient cooperation and green integrated transportation system [2]. Germany implemented the Federal Transport Infrastructure Plan national strategy that considers the natural environment, regional development, and overall interests of urban construction, comprehensively, to construct a low-emission, low-cost, high efficiency, highly synergistic environment-friendly transport network [3]. Japan considered the Integrated Transport Policy System as a strategic orientation and focused on the overall planning of traffic and intensification of transportation to achieve an efficient and orderly integrated transportation management by constructing inland, coastal, aviation, and other integrated transportation three-dimensional structures [4]. In summary, the frontier of the field of integrated transportation engineering science and technology of foreign advanced countries involves promoting an integrated transportation system to network integration, synergy, and intelligent development with safe, efficient, and green as the core. Additionally, China considered Comprehensive Transportation Network Medium- and Long-Term Development Plan as the core to clearly propose medium- and long-term development goals and tasks of the integrated transportation infrastructure network. Thus, it promotes various modes of transportation from a local optimal to an overall optimal and improves the overall efficiency and comprehensive benefits of the transportation system [5].

\subsection{Worldwide development prospect of integrated transportation engineering technology in 2035}

With respect to the year 2035, the field of integrated transportation engineering science and technology is expected to include several disruptive technologies with the prospect of a major industry revolution including the Beidou satellite positioning and navigation system, 5G communication, trusted computing, mobile Internet, cloud computing, big data, Internet of Things (IoT), and the space traffic communication network. The deep application and cross-border integration of next-generation information technology will promote revolutionary changes in production and development modes of integrated transportation. Integrated transportation infrastructure, transport modes, operation management, and services will generate a new format and pattern given the deep penetration of new-generation information technology. For example, land, sea, and air transportation resources will be fully integrated under the support of information technology to form a collaborative and intelligent three-dimensional integrated transportation system that shares information, coordinates resources, and provides complementary advantages. The vehicle rapidly transforms to intelligence. Unmanned driving, remote driving, air-ground integrated three-dimensional traffic, and other new transportation systems will continue to emerge and gradually gain access to public daily life. Mobile Internet and big data technology will effectively support integrated transportation information in acquisition, interaction, integration, and decision-making. Coordination of organization between system elements of the same transport modes and connectivity and comprehensive coordination between different transport modes will significantly improve the service quality and scientific management ability of the transportation industry.

\section{Demand analysis of China's integrated transportation engineering science and technology in 2035}

\subsection{China's economic and social development scenario in 2035}

As a pioneer and service industry in economic and social development, integrated transportation functions as a foundation and important link of social and economic activities. In 2035 , China's huge economy and population will necessitate a suitable transport supply capacity. It is also necessary to elevate service quality and safety of transportation to a new level when the quality of life improves. Harsh energy-saving environmental protection needs will drive the operation efficiency of the integrated transportation system as it continues to improve.

The continuous improvement of the integrated transportation engineering science and technology will increase efficiency, safety, energy-saving, and environmental protection of the transportation system to a new level and will also promote transformation, upgrade, and sustainable development of transportation infrastructure, transportation tools, operation management, transportation, and travel services.

\subsection{Major problems and demands in integrated transportation engineering science and technology}

With respect to the year 2035, China's comprehensive national strength will continue to improve, and the acceleration of new industrialization, informatization, urbanization, and agricultural modernization will result in a strong demand for transportation services. The major issues faced by the development of integrated transportation engineering science and technology are as follows: coordinating the organization of different modes of transportation to improve operational efficiency and service quality; ensuring that traffic system elements collectively function to enhance the safety level of the traffic system and achieve a target of zero traffic accident deaths; and reducing the energy consumption and emissions of transportation and the impact of the traffic system on the environment. The fore-mentioned major issues lead to new and important demands for scientific and technological innovation in the field of integrated transportation engineering as follows: 
(1) Improve the road traffic, rail transportation, water transport, and air transport infrastructure and integrated hub and integrate the advantages of resources in the traffic system and build an optimal combination of various modes of transportation to coordinate organization, competition, and cooperative development of an integrated transportation system to satisfy urban agglomeration, urban belt, and urbanization development of transportation needs.

(2) Construct a transportation network technology system that provides a better travel information service for passenger and cargo transport and satisfy diverse, personalized, and dynamic needs of passenger travel and logistics to enhance the synergies of integrated transportation operation services.

(3) Enhance the level of automation, intelligence, and synergistic operation of carrier tools and promote the construction and development of new intelligent air-ground integrated transportation systems that utilize unmanned and remote driving as primary tools to enhance the active prevention and control of traffic accidents.

(4) Ensure complete use of mobile Internet, big data technology, and cloud computing platforms to perform effective management, analysis, sharing, and application of the integrated transportation multi-perception sensing data. Promote the docking of various traffic information service platforms and the establishment of a traffic sharing travel mode to provide accurate, user-friendly, and integrated transportation information services for the public.

(5) Analyze population migration laws, public travel needs, hub passenger flow scale, and transportation characteristics to provide support to optimize the planning and construction of integrated transportation facilities, safe operation control, and integrated transportation management and decision-making. A series of technical and management methods should be used to continuously reduce the energy consumption of the transportation system and adverse effects on the environment.

\section{Technology foresight and development capability analysis on the integrated transportation engineering science and technology}

The "Development Strategy for China's Integrated Transportation Engineering Science and Technology to 2035" project team utilized expert discussions and the Delphi method as the primary processes by means of literature metrology, and patent analysis for technical support. A list of alternative technologies was developed around organization and optimization, collaborative services, and three key directions of the new-generation integrated transportation system based on the analysis of the development trend of integrated transportation engineering science and technology, major scientific and technological requirements, and major development focus in the field for the next 5-20 years. Additionally, a broadly representative network of survey experts was formed, and two rounds of Delphi investigations were conducted. Finally, eight key technologies were summarized that significantly affect the development of integrated transportation engineering science and technology (Table 1).

The results of the survey and statistical analysis indicate that the general characteristics of the technical development direction of integrated transportation engineering science and technology are summarized as follows:

(1) In the aspect of core technology as shown in Table 2, collaborative unmanned and operational optimization technology ranked higher, and this is an important indicator of national scientific research strength and industrial level. However, the technology by itself and the existing traffic system exhibit a certain degree of discontinuity. Both integrated transportation big data multi-perception and real-time collaborative processing technology and integrated transportation information service technology in a mobile Internet environment ranked higher in terms of technical versatility and driving ability. This suggests that the direction of the technology application range is relatively wide

Table 1. List of key technologies for integrated transportation engineering science and technology.

\begin{tabular}{|c|c|c|}
\hline \multirow{2}{*}{ Key directions } & \multicolumn{2}{|r|}{ Key technologies } \\
\hline & No. & Name \\
\hline \multirow[t]{3}{*}{ Integrated transportation organization and optimization } & 1 & $\begin{array}{l}\text { Cooperative organization and operation optimization technology of } \\
\text { integrated transportation hub }\end{array}$ \\
\hline & 2 & Intelligent technology of the multimodal transport of goods \\
\hline & 3 & Passenger integration travel technology \\
\hline Integrated transportation collaborative services & 5 & $\begin{array}{l}\text { Integrated transportation information service technology in a mobile } \\
\text { Internet environment }\end{array}$ \\
\hline \multirow[t]{2}{*}{ New-generation integrated transportation system } & 6 & Cooperative unmanned and operational optimization technology \\
\hline & 7 & $\begin{array}{l}\text { Remote driving and intelligent operation technology in a mobile } \\
\text { Internet environment }\end{array}$ \\
\hline
\end{tabular}


Table 2. Statistics results for integrated transportation engineering science and technology key technology importance index sort.

\begin{tabular}{|c|c|c|c|c|c|c|c|}
\hline Key technology item & Core & Commonality & $\begin{array}{c}\text { Driving } \\
\text { ability }\end{array}$ & Discontinuity & $\begin{array}{c}\text { Economic } \\
\text { development } \\
\text { importance }\end{array}$ & $\begin{array}{c}\text { Social } \\
\text { development } \\
\text { importance }\end{array}$ & $\begin{array}{c}\text { National } \\
\text { defense and } \\
\text { state security }\end{array}$ \\
\hline $\begin{array}{l}\text { Cooperative organization and } \\
\text { operation optimization technology } \\
\text { of integrated transportation hub }\end{array}$ & 6 & 3 & 6 & 6 & 1 & 2 & 7 \\
\hline $\begin{array}{l}\text { Intelligent technology of } \\
\text { multimodal transport of goods }\end{array}$ & 7 & 6 & 8 & 7 & 3 & 3 & 6 \\
\hline $\begin{array}{l}\text { Passenger integration travel } \\
\text { technology }\end{array}$ & 8 & 4 & 5 & 8 & 2 & 1 & 8 \\
\hline $\begin{array}{l}\text { Integrated transportation big } \\
\text { data multi-perception and real- } \\
\text { time collaborative processing } \\
\text { technology }\end{array}$ & 2 & 2 & 1 & 4 & 4 & 4 & 5 \\
\hline $\begin{array}{l}\text { Integrated transportation } \\
\text { information service technology in } \\
\text { the mobile Internet environment }\end{array}$ & 3 & 1 & 2 & 5 & 5 & 7 & 3 \\
\hline $\begin{array}{l}\text { Cooperative unmanned and } \\
\text { operational optimization } \\
\text { technology }\end{array}$ & 1 & 7 & 3 & 2 & 6 & 5 & 4 \\
\hline $\begin{array}{l}\text { Remote driving and intelligent } \\
\text { operation technology in mobile } \\
\text { Internet environment }\end{array}$ & 5 & 8 & 7 & 3 & 8 & 8 & 2 \\
\hline $\begin{array}{l}\text { Air-ground integrated unmanned } \\
\text { intelligent transportation system } \\
\text { technology }\end{array}$ & 4 & 5 & 4 & 1 & 7 & 6 & 1 \\
\hline
\end{tabular}

and exhibits strong intersectionality that covers all common technology areas of integrated transportation engineering science and technology and displays a wide industry-driven range. In terms of the importance of economic and social development, the related technology of integrated transportation organization and optimization ranked higher, thereby revealing close contact between the integrated transportation service system and livelihood of individuals. Moreover, air-ground integrated unmanned intelligent transportation system technology is directly related to the development of transportation vehicles, infrastructure, and management services, and includes a high index for national protection and defense security importance.

(2) With respect to time as shown in Fig. 1 (key technical item number corresponds to Table 1), it is expected that China's key technology of integrated transportation engineering science and technology will be achieved in 2025-2030. The time span of technology realization to social realization corresponds to an average of approximately two years, and the overall technology realization time is after the world technology realization time of approximately $3-5$ years.

(3) In terms of technological development and constraints, the US possesses leading-edge technology in the field of integrated transportation engineering science and technology, and it is followed by the EU and Japan. Overall, R\&D investment, talent, science, and technology resources, capability of industrial bases, and coordination and cooperation are the main restrictive factors of technology development in the field of integrated transportation engineering science and technology (Fig. 2).

\section{Overall strategies of integrated transportation engineering science and technology development}

\subsection{Development ideas}

China's strategic positioning involves supporting the innovation and development of new urbanization, adapting to major changes in regional collaborative development model, fulfilling the responsibility of developing ecological green, and supporting sustainable development of the national economy. It is important for China to adhere to the development ideas of "supply and demand balance, fast and comfortable, collaborative services, safe and reliable, intelligent and efficient." The major approaches include mobile Internet, traffic big data, cloud computing, and other technologies. The principal characters of development include network connections, collaboration, and intelligence. The major targets involve enhancing the collaborative operation level of the integrated transportation, service quality, and active safety and security capabilities. Finally, it is expected that China will achieve innovative development in integrated transportation engineering science and technology.

\subsection{Strategic targets}

\subsubsection{Targets for the year 2025}

First, it is expected that China's integrated transportation will achieve a high degree of network connections, collaboration, and intelligence, and a modern integrated transport network with 


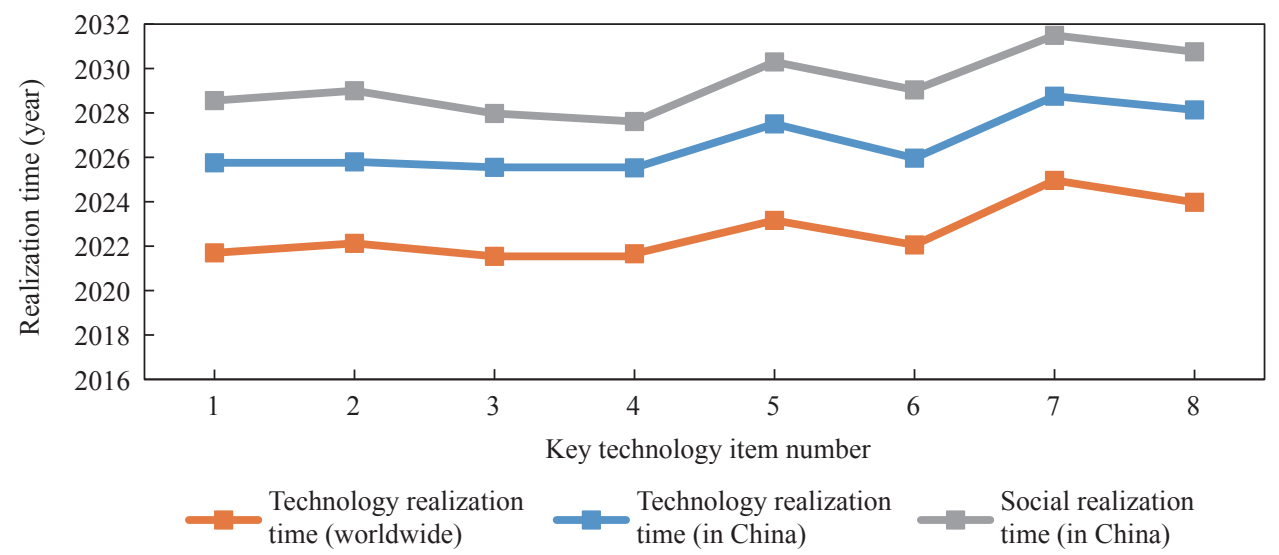

Fig. 1. Comparative analysis of the anticipated time of key technologies in integrated transportation engineering science and technology.

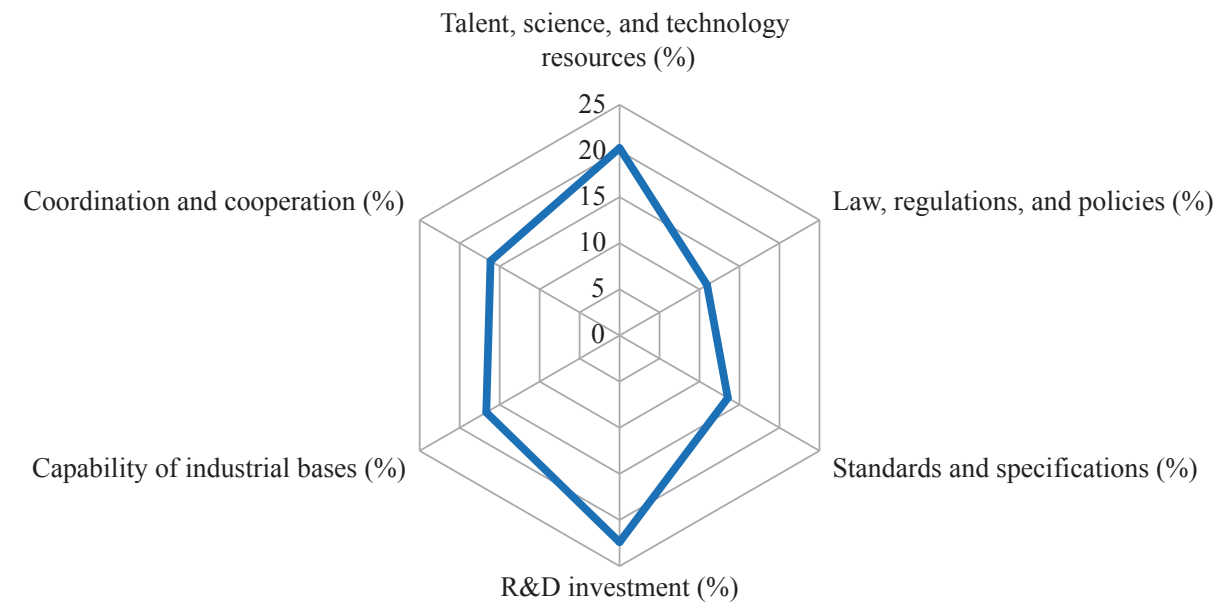

Fig. 2. Analysis of the restrictive factors corresponding to the development of integrated transportation engineering science and technology.

a rational layout of space and a clear layer of structure and that a smooth functional connection will be constructed. Second, it is expected that a reasonable proportion will be shared among various modes of transportation, and technical equipment will be in sync with the advanced international level. Third, it is expected that the use of mobile Internet, big data, cloud computing, IoT, and other technologies will achieve information interoperability among various modes of transportation, thereby significantly improving transportation and information services.

\subsubsection{Targets for the year 2035}

First, it is expected that the integrated transportation engineering science and technology will exhibit significant progress in network connections, collaboration, and intelligence, and that the transportation infrastructure and technical equipment will achieve an advanced international level. Additionally, improvements in collaborative organization and operation optimization among the various modes of transportation are expected. Thus, an integrated transportation service system will be formed. All the forementioned factors will strongly support China's economic growth and social progress. Second, a basic balance between the comprehensive traffic supply and demand and the effective alleviation of traffic congestion are expected. Third, the means of transportation will share their information with each other, and this will provide a seamless convergence of high-quality, differentiated, intelligent, and integrated information services.

\section{Key directions and development routes of integrated transportation engineering science and technology}

\subsection{Development targets}

"Collaborative operation" and "intelligent service" correspond to the targets of the integrated transportation engineering science and technology 2035 development strategy while "integrated transportation organization and optimization," "integrated transportation collaborative services," and "new-generation integrated transportation system" correspond to the key directions of the integrated transportation engineering science and technology 2035. 


\subsection{Key directions and development routes}

The key directions of integrated transportation engineering science and technology for the year 2035 include the following:

(1) Integrated transportation organization and optimization

In the next 20 years, China's urbanization will continue with rapid development of motorization. Thus, the transportation demand will continue to grow. To solve the gap between supply and demand, it is necessary for China to conduct research on the cooperative organization and operation optimization of the integrated transportation hub, intelligent technology of multimodal transport of goods, passenger integration travel technology, and other technologies to improve overall transportation efficiency.

(2) Integrated transportation collaborative services

The main objective of integrated transportation development involves continuously improving service quality. Improvements are expected in the auxiliary decision-making ability of data and information with the support of big data and mobile interconnection technology. Alternatively, research on multi-perception and real-time collaborative processing of integrated transportation big data, and integrated transportation information service in the mobile Internet environment and other technologies should focus on improving service quality.

(3) New-generation integrated transportation system

With the rapid progress of technology and development of intelligent transportation, network connections, unmanned vehicles, and other technologies will constitute the support of future transportation. Additionally, a new air-ground integrated three-dimensional transportation system will be established. Meanwhile, research on cooperative unmanned and operational optimization technology, remote driving, and intelligent operation technology in the mobile Internet environment as well as three-dimensional unmanned intelligent transportation systems, and other technologies will focus on enhancing the integrated transportation intelligence and security level.

The overall technical development route is shown in Fig. 3.

\section{Basic research direction of priority deployment}

A developing trend and key direction corresponds to

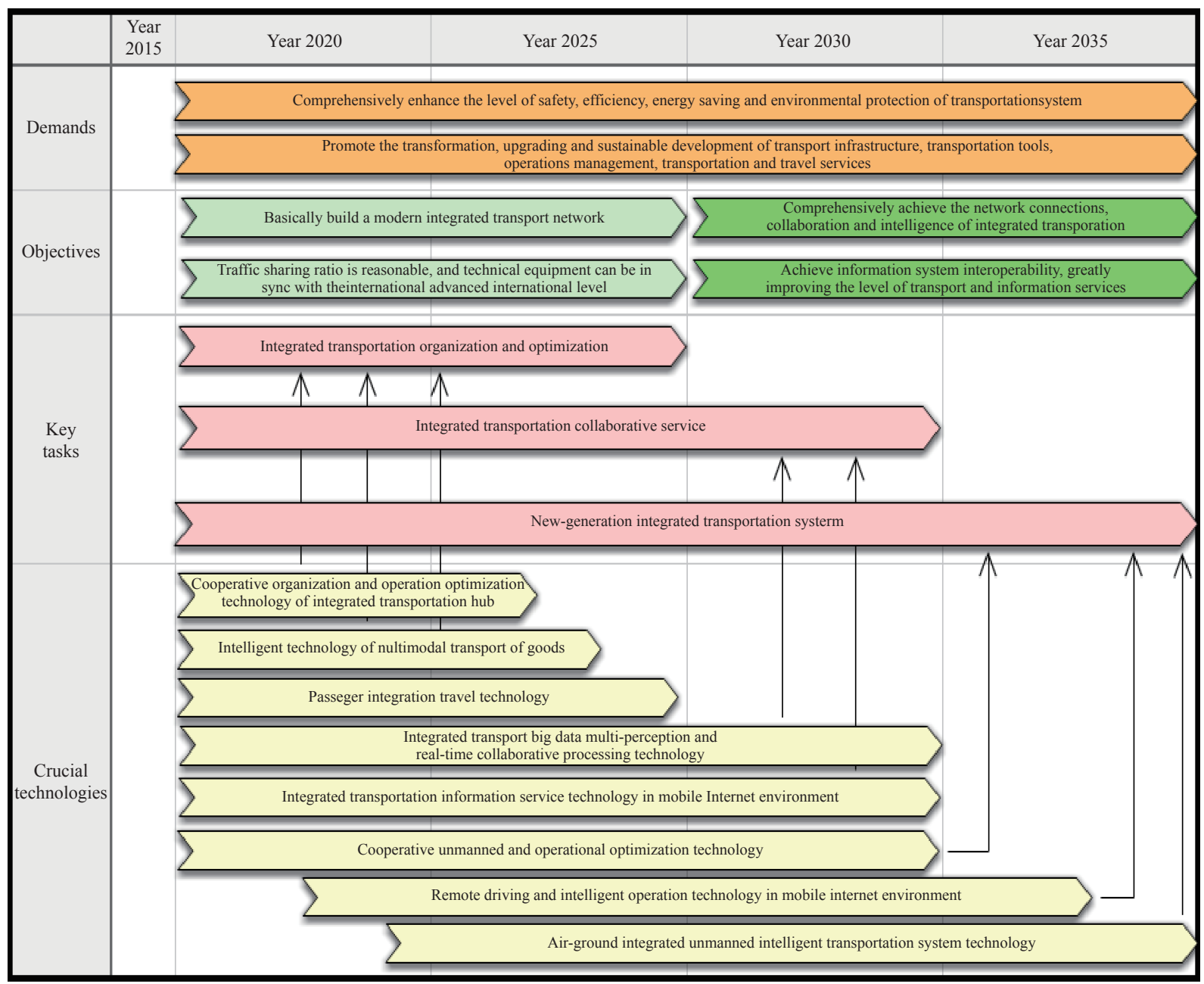

Fig. 3. Overall technical development route of integrated transportation engineering science and technology for the year 2035 . 
strengthening the basic research direction supporting the future development of engineering science and technology. Based on technological breakthroughs and common technology research requirement, we extensively solicited opinions and organized experts for discussion. We eventually determined that the basic research direction of integrated transportation engineering science and technology development required prior deployment.

\subsection{Supply and demand balance of the integrated transportation system}

The main research directions include an integrated transportation network topology mechanism and dynamic problems, a supply and demand balance theory and method of the integrated transportation system in a mobile Internet environment, and multi-mode space-time dynamic traffic behavior analysis and demand guidance given the background of big data.

\subsection{Mechanism of traffic behavior and driving behavior}

The major research directions include driving psychology and behavior under a cooperative vehicle infrastructure system environment, traffic flow theory reconstruction and multi-resolution modeling and simulation under a man-machine drive environment, people-vehicle-route coupling mechanism and vehicle cooperative control, and unmanned vehicle travel sharing organization and optimization.

\subsection{Coordinated operation and decision optimization of the integrated transportation system}

The main research directions include a multiscale collaborative operation and organization optimization methods of an integrated transport hub, construction of a space-air-ground integrated network and high reliability integrated transportation information interaction, information security protection theory and methods of intelligent network-connected vehicles as well as a new-generation traffic signal optimization theory, and methods under network connection conditions.

\section{Major projects of mobile integrated transportation system}

\subsection{Demand and necessity}

China proposed the "Belt and Road," "Beijing-Tianjin-Hebei coordinated development," "Yangtze River Economic Zone," and other major development strategies that consider transportation as the first field. The State Council's action guidance actively promoted the "Internet Plus" to clearly propose two key actions of "Internet Plus" efficient logistics and "Internet Plus" convenient traffic. The implementation of the above strategies imposes higher requirements on an integrated transportation system. In the new mobile Internet situation, it is imperative to construct a mobile Internet integrated transportation system with the idea of "Internet Plus" and realize the main goal of ensuring that integrated transportation engineering science and technology is networked, collaborative, and intelligent as fast as possible.

\subsection{Engineering tasks}

An integrated transportation big data system, a travel and logistics integrated service system, and an integrated transportation control system should be established based on the mobile Internet environment. Moreover, the integrated transportation coordination services and control system should be rebuilt.

The four modes of transport covering roads, railways, aviation, and waterways as well as a traffic league perception system including the main transport infrastructure and all carrying tools should be set up. Moreover, an integrated transportation data system should be established by breaking through efficient acquisition and security management technology of cross-domain, full-time, and integrated transportation big data, association and mining technology of integrated transportation big data, and other key technologies.

A cross-traffic, cross-regional, cross-border travel, and logistics integrated service system should be established by breaking through integrated transportation system operating status identification and travel intelligent decision-making, multi-traffic collaborative services, and other key technologies.

Cross-traffic and cross-regional integrated transportation control facilities, and a multi-level integrated transportation control system should be set up by breaking through cross-regional transportation system collaborative optimization and efficient organization, integrated transportation system operation safety and emergency protection, and other key technologies.

\subsection{Project objectives and effects}

In 2025, it is expected that the integrated transportation big data system, and travel and logistics transportation integrated service system will be established. The mobile Internet terminal will receive real-time accurate dynamic traffic information. The transportation infrastructure, carrying tools, and operation information will be online. Thus, significant support will be afforded to efficient logistics and a convenient travel collaboration service. The proportion of integrated transport costs to the total cost of social logistics will be reduced to $51 \%$. The passenger transfer efficiency will increase by $8 \%$. The freight forwarding efficiency will increase by $50 \%$. The integrated transportation energy consumption will account for $20 \%$ or less of the total costs. Big city peak travel time will reduce by $5 \%$. Heavy major traffic accidents will be decreased by $20 \%$.

In 2035, the cross-traffic, cross-regional integrated trans- 
portation control system will be established, and several traffic modes will communicate with each other and achieve co-control. Thus, this will comprehensively upgrade the intelligence level of the integrated transportation control system. The proportion of integrated transport costs to the total cost of social logistics will be reduced to $50 \%$. The passenger transfer efficiency will increase by $10 \%$. The freight forwarding efficiency will increase by $60 \%$. The integrated transportation energy consumption will account for not more than $18 \%$ of the total costs. Big city peak travel time will reduce by $10 \%$. Heavy major traffic accidents will decrease by $30 \%$.

\section{Major engineering science and technology special projects of an unmanned traffic system}

\subsection{Demand and necessity}

The deep integration of information technology, artificial intelligence, wireless communications technology, and transportation leads to revolutionary changes in the transportation system. An unmanned vehicle is the carrier of emerging technology centralized application and testing, provides significant impetus to the new technological revolution, and will become the most significant intergenerational characteristic of the new-generation transportation system. Research on unmanned traffic systems is necessary to promote new-generation transportation system innovation and technological advancement and strategic high-tech industries.

\subsection{Tasks and route of key technologies}

The key technologies and tasks of unmanned traffic systems include: a carrier with unmanned driving technology, infrastructure structured and digital technology, space-air-ground integrated network technology, and networked unmanned traffic cooperative operation technology.

In 2016-2025, research should focus on carriers with unmanned driving technology, infrastructure structured and digital technology, and space-air-ground integrated network technology to provide a basis for the construction of unmanned traffic systems.

In 2020-2030, it is necessary to promote the research and development of collaborative operation technology in the same mode of transportation to achieve network collaborative operation in the same mode of transportation.

In 2025-2035, it is necessary to promote the research and development of cross-traffic collaborative operation technology and build an unmanned three-dimensional logistics integrated demonstration application system with air-ground coordination technology.

\subsection{Goals and landmark results}

In 2025, several unmanned vehicles, trains, ships, aerial vehicles, and other carrying tools will be used, and the market penetration of the unmanned vehicles with a highly or fully automated driving assistance system will exceed $25 \%$. The traffic infrastructure is adapted to unmanned driving, and it will achieve structuring and digitalization of the basic realization. A cross-layer, cross-regional, and cross-way interaction and high reliability and low latency space-air-ground integrated transportation information network will be established, and the wide use of integrated transportation information intelligent service platforms will be incorporated.

In 2035, an unmanned traffic system with a networked collaborative operation function in the same mode of transportation will be established, wherein the market penetration of the unmanned vehicles with a highly or fully automated driving assistance system exceeds $50 \%$. The cooperative vehicle infrastructure systems, ship infrastructure systems, and other technologies will be widely used. Furthermore, an unmanned three-dimensional logistics system with unmanned aerial vehicles and unmanned vehicles will be set up to demonstrate the application of cross-traffic network collaborative operation technology.

\section{References}

[1] Federal Transportation Advisory Group (FTAG) of United States. Vision 2050: An integrated national transportation system [R]. Washington DC: FTAG, 2001. Chinese.

[2] European Commission, Directorate-General for Mobility and Transport. Transport white paper [R]. Brussels: European Commission, Directorate-General for Mobility and Transport, 2011. Chinese.

[3] Federal Ministry of Transport, Building and Housing. Federal transport infrastructure plan [R]. Berlin: Federal Ministry of Transport, Building and Housing, 2003. Chinese.

[4] Ministry of Land, Infrastructure and Transport (MLIT). Integrated transport policy system [R]. Tokyo: MLIT, 2012. Chinese.

[5] National Development and Reform Commission of the People's Republic of China. Comprehensive transportation network medium and long-term development plan [R]. Beijing: National Development and Reform Commission of the People's Republic of China, 2007. Chinese. 